\title{
Micromechanical impact of solidification regions in ductile iron revealed via a 3D strain
} partitioning analysis method

\author{
Xu, C. L.; Andriollo, T.; Zhang, Y. B.; Hernando, J. C.; Hattel, J.; Tiedje, N.
}

Published in:

Scripta Materialia

Link to article, DOI:

10.1016/j.scriptamat.2019.12.018

Publication date:

2020

Document Version

Peer reviewed version

Link back to DTU Orbit

Citation (APA):

Xu, C. L., Andriollo, T., Zhang, Y. B., Hernando, J. C., Hattel, J., \& Tiedje, N. (2020). Micromechanical impact of solidification regions in ductile iron revealed via a 3D strain partitioning analysis method. Scripta Materialia, 178, 463 - 467. https://doi.org/10.1016/j.scriptamat.2019.12.018

\section{General rights}

Copyright and moral rights for the publications made accessible in the public portal are retained by the authors and/or other copyright owners and it is a condition of accessing publications that users recognise and abide by the legal requirements associated with these rights.

- Users may download and print one copy of any publication from the public portal for the purpose of private study or research.

- You may not further distribute the material or use it for any profit-making activity or commercial gain

- You may freely distribute the URL identifying the publication in the public portal 
See discussions, stats, and author profiles for this publication at: https://www.researchgate.net/publication/338337363

\section{Micromechanical impact of solidification regions in ductile iron revealed via a 3D strain partitioning analysis method}

Article in Scripta Materialia · December 2019

DOI: $10.1016 /$ j.scriptamat.2019.12.018

\section{CITATIONS}

6 authors, including:

Tito Andriollo

Technical University of Denmark

26 PUBLICATIONS 165 CITATIONS

SEE PROFILE

Juan Carlos Hernando

Jönköping University

14 PUBLICATIONS 68 CITATIONS

SEE PROFILE
118

Yubin Zhang

Technical University of Denmark

121 PUBLICATIONS 985 CITATIONS

SEE PROFILE

J.H. Hattel

Technical University of Denmark

308 PUBLICATIONS 5,924 CITATIONS

SEE PROFILE

Some of the authors of this publication are also working on these related projects:

Project Engineering Computational Modeling of Nanoscale Phenomena View project

Reliable and optimized additive manufacturing through numerical process modelling View project 


\title{
Micromechanical impact of solidification regions in ductile iron revealed via a
}

\section{D strain partitioning analysis method}

\author{
C.L. Xu ${ }^{1}$, T. Andriollo ${ }^{1 *}$, Y.B. Zhang ${ }^{1}$, J.C. Hernando ${ }^{2}$, J. Hattel ${ }^{1}$, N. Tiedje ${ }^{1}$ \\ ${ }^{1}$ Department of Mechanical Engineering, Technical University of Denmark, Denmark \\ ${ }^{2}$ Department of Materials and Manufacturing, School of Engineering, Jönköping University, Sweden \\ * Corresponding author. Full address: Produktionstorvet, Building 425, room 225, 2800 Kgs. Lyngby, \\ Denmark. Phone: +45 452547 22. E-mail: titoan@mek.dtu.dk
}

\section{Abstract}

Strain partitioning between first-to-solidify (FTS) and last-to-solidify (LTS) regions upon tensile loading of ductile iron was investigated by combining in-situ X-ray tomography with digital volume correlation and post-mortem metallographic examinations. The results indicate that the plastic shear bands form mainly by linking graphite particles contained in the same FTS region. A special distance function is introduced to show that this is due to the lower strength of the FTS regions compared to the LTS regions, but also to the higher stress concentration associated with the particles. The methodology is general and therefore extendable to material systems containing similar microstructural heterogeneities.

\section{Keywords}

Digital volume correlation; Micromechanics; Cast iron; Solidification microstructure; Strain distribution

\section{Main text}

Ductile iron (DI) is widely used in key industrial sectors like transport and energy production due to its high performances and versatility at relatively low cost compared to steels with analogous performances [1]. The further expansion of the material application realm is constrained by the limitations in terms of reliability and range of applicability of the microstructure-property relations available in the literature, which are rooted in the still incomplete understanding of the mechanisms controlling deformation and fracture at the microscale [2]. A reason for this is the challenge represented by the complex microstructure of $\mathrm{DI}$, which, at room temperature, consists of graphite particles called nodules embedded in a matrix of ferrite and pearlite, whose relative fractions depend on chemistry and processing conditions. In this respect, most of the past studies have focused on establishing relations between the macroscopic mechanical behavior of DI and the average parameters of the individual microstructural phases, e.g. the average graphite fraction, 
average graphite nodularity, average ferrite grain size, etc. [3].

This approach has the advantage of leading to well-defined average values of the microstructural parameters, but the disadvantage of neglecting the variations in the spatial distribution of the microstructural phases which occur at intermediate length-scales. Indeed, it is well-known that the process of solidification of DI leads to the formation of first-to-solidify (FTS) and last-to-solidify (LTS) regions characterized by different average values of the microstructural parameters. For instance, the FTS regions tend to be richer in ferrite and to contain larger nodules, whereas the LTS regions are richer in pearlite and are the preferred location for porosities and oxides [4].

Recent empirical studies have shown that the change in the morphology of the FTS regions can impact significantly the tensile properties of cast irons even when the average fraction of the microstructural phases computed over the entire specimen remain mostly unaffected [5]. However, compelling micromechanical evidence unveiling the mechanisms by which the FTS and LTS regions can impact the deformation and fracture process of DI has not been reported so far. To the authors' best knowledge, the only studies on this topic were conducted by Fernandino et al. by means of 2D micromechanical simulations [6] and in-situ surface observations supported by digital image correlation [7]. These authors concluded that, during tensile loading of DI, the subdivision between FTS and LTS regions does not play a role at strains below $1 \%$, whereas it becomes important towards the end of the tensile test in determining the fracture path. However, the same authors remarked that the latter conclusion should be taken with care, as observations limited to the specimen's surface do not allow to account for the presence of sub-surface graphite particles, which are known to act as crack initiators and attractors [8]. Moreover, it is worth pointing out that conclusions valid at the surface level might not hold for the bulk of $\mathrm{DI}$, due to differences in the microstructural stress state $[9,10]$. Also, 2D micromechanical simulations of the DI behavior during tensile loading can differ from the corresponding 3D simulations, due to the inherent threedimensional nature of the material microstructure [11].

In the present work, in order to exclude the possible effects of the sample surface, a 3D analysis of the strain partitioning during tensile loading of DI was carried out to investigate the mechanisms by which the subdivision into FTS and LTS regions can impact the mechanical properties at the macro-scale. The analysis is based on a novel combination of in-situ X-ray tomography, digital volume correlation and post-mortem metallographic examinations which is extendable to other similar material systems, e.g. metal-matrix composites.

First, a miniaturized dog-bone shaped tensile specimen with a gauge length of $10 \mathrm{~mm}$ and a cross-section of $1 \times 2 \mathrm{~mm}^{2}$ was extracted from a large DI component, see Figure 1 . The main alloying 
elements besides Fe were C (3.68 wt\%), Si (2.3 wt\%), Mn (0.22 wt\%) and Mg (0.11 wt\%). The microstructure of the specimen consisted of almost spherical graphite nodules embedded in a matrix of ferrite and pearlite, with a fraction of the latter of about $5 \%$. The volume fraction and average size of the graphite nodules were $11.5 \%$ and $30 \mu \mathrm{m}$, respectively. The specimen was mounted on a tensile test rig inside a Zeiss Xradia 520 Versa micro-computed tomography system and loaded in tension up to $\approx 10 \%$ macroscopic strain. 3D scans with voxel size $1.358 \mu \mathrm{m}$ were taken at both the beginning and the end of the test, which were segmented to separate the nodules from the matrix and used to calculate the displacement at the microstructural level by means of global digital volume correlation (DVC) [12]. After the tensile test, an internal Y-Z section of the specimen located $\approx 120 \mu \mathrm{m}$ from the lateral surface - see Figure 1 - was ground, polished and color etched using a picric-based solution sensitive to $\mathrm{Si}$ segregation to reveal the subdivision of the microstructure into FTS and LTS regions [13].

Figure 2 shows an optical image of the abovementioned $Y-Z$ section of the specimen after color etching. The colors are proportional to the thickness of the layer formed upon reaction with the picric-based solution and allow differentiating the FTS regions (white-blueish colors) from the LTS regions (yellow-brownish colors). It can be observed that the FTS regions contain almost exclusively large nodules and ferritic grains. The pearlitic structures are concentrated in the LTS regions, where, in addition, smaller nodules and a large number of small porosities $(<10 \mu \mathrm{m})$ are seen (see Figure 2 (b)). All these features are common for DI [4]. The damage caused by the tensile test is revealed by the extensive debonding along the portion of the graphite-matrix interface perpendicular to the loading direction. This form of damage is similar to that identified in previous works focusing on DI grades with low pearlite to ferrite ratio [14].

The von Mises equivalent strain determined based on the DVC analysis over the same Y-Z section of the specimen is shown in Figure 3 (a). It is worth remarking that, despite the bi-dimensional appearance of the contour, the strain has 3D nature, as it associated with the displacement field reconstructed with DVC. It is clearly observed that the strain localizes in bands which are oriented at most places at approximately 45 degrees with respect to the loading direction. However, in contrast to theoretical expectations based on the hypothesis of homogenous material behavior, the individual bands do not run over the entire width of the specimen. Rather, each band seems to have developed over a limited distance by linking some neighboring nodules. Low-strain areas can be observed in between the bands, where the strain values are lower than the macroscopic value of $10 \%$.

In order to further investigate the nature of the strain bands, the strain pattern was compared 
with the spatial distribution of the FTS and LTS regions, retrieved by segmenting the color-etched microstructure of Figure 2 via multi-thresholding (see Figure S1 in the supplementary material). The strain values within the FTS and the LTF regions are shown in Figure 3 (b) and Figure 3 (c), respectively. It can be observed that the most of the highly strained bands are localized in the FTS regions (Figure $3(b)$ ) and that the boundaries of the former coincide with the boundaries of the latter. That is, the discontinuous nature of the strain bands is related to the subdivision of the microstructure into FTS and LTS regions. Accordingly, the low-strain areas are mainly within the LTS regions, which appear to act as "hard" spots in the microstructure. This fact is further emphasized by the distributions of the strain values in the FTS and LTS matrix regions reported in Figure $3(d)$. Indeed, despite the two distributions show a similar shape, a significant shift in the mean values exists, confirming that the matrix in the LTS regions deforms less than in the FTS regions.

The difference in the mean level of deformation between the matrix zones associated with the FTS and the LTS regions can stem from several factors. The most obvious is the disparity in mechanical properties arising from fundamental metallurgical differences like pearlite to ferrite ratio, micro-segregation, etc. (see Figure 2). Fernandino et al. estimated, via nano-indentation tests, that in ferritized DI the matrix yield strength in the LTS regions can be $\approx 80 \mathrm{MPa}$ higher than that in the FTS regions [6]. A second factor relates to the matrix spatial distribution with respect to the nodules and the porosities, which act as stress concentrators during tensile loading [15]. That is, they create a stress concentration in the matrix whose intensity depends, to a first approximation, on the ratio between the distance to and size of the nodule/porosity. As larger nodules are present in the FTS regions, the stress concentration in the surrounding matrix is expected to affect a more extended volume. Finally, it is worth noting that the nodules are surrounded by a residual stress field forming during solid-state cooling that can cause premature yielding of the matrix upon tensile loading $[16,17]$. However, this effect is relevant at small strains only, meaning that the presence of the residual stress field should be negligible in this particular case.

The above discussion indicates that the larger deformation exhibited by the matrix in the FTF regions may be due to the difference in mechanical properties, but also to the difference in average stress concentration. In order to evaluate the individual contribution of these two factors, a special 3D distance function was introduced as follows. For each point $\boldsymbol{x}$ in the matrix, the distance $d_{i}$ to the particle $i$ and the particle equivalent radius $R_{i}$ were computed via standard image processing algorithms applied to the segmented tomography scan. This operation was repeated for all the particles in the microstructure, considered as the sum of the nodules plus all the porosities larger than $5 \mu \mathrm{m}$. The normalized distance $\tilde{d}$ at $\boldsymbol{x}$ was then defined as: 


$$
\tilde{d}(\boldsymbol{x})=\min \left\{\frac{d_{1}(\boldsymbol{x})}{R_{1}}, \frac{d_{2}(\boldsymbol{x})}{R_{2}}, \ldots, \frac{d_{n}(\boldsymbol{x})}{R_{n}}\right\}
$$

where $n$ is the total number of particles. The quantity $\tilde{d}(\boldsymbol{x})$ is assumed to give an indication of the stress concentration at point $\boldsymbol{x}$ and, more specifically, the smaller the value of $\tilde{d}(\boldsymbol{x})$, the higher the expected stress concentration.

Figure 4 (a) shows a contour of the normalized 3D distance function $\tilde{d}$ over the same Y-Z section of the specimen considered previously. Based on the contour data, the matrix points on the $\mathrm{Y}-\mathrm{Z}$ section were classified into eight bins corresponding to distinct intervals of $\tilde{d}$. The outcome of this binning procedure was subsequently used to calculate, for each bin, the area occupied by the bin points overlapping the FTS and the LTS regions, respectively. The results are shown in Figure 4 (b), where the area values are normalized by the total area occupied by the matrix. It can be seen that, for bins spanning low values of $\tilde{d}$, the fraction of matrix area overlapping the FTS regions is larger than that overlapping the LTS regions, while for bins spanning high values $\tilde{d}$ the opposite holds true. Given the meaning of the normalized distance $\tilde{d}$, this leads to the conclusion that the matrix in the FTS regions is, on average, subjected to higher stress concentration than the matrix in the LTS regions.

At this point, the question of whether there is a difference in mechanical properties between the matrix in the FTS regions and the matrix in the LTS regions arises, as the higher stress concentration in the former might be sufficient to explain its larger deformation upon tensile loading. To shed light on this aspect, the output of the binning procedure was combined with the strain data of Figure 3 (a) to compute, for each bin, the mean strain of the bin points overlapping the FTS and the LTS regions, respectively. Figure 4 (c) shows that, for all the bins, the mean strain associated with the FTS regions is always larger than that associated with the LTS regions. As the values of $\tilde{d}$ are similar within a certain bin, it follows that the points belonging to the bin are approximately subjected to the same stress concentration. Consequently, the systematically higher values of the mean strain associated with the FTS regions can only be explained by weaker mechanical properties of the matrix.

In conclusion, with respect to the investigated DI, strain bands form in the matrix upon tensile loading that link nodules belonging to the same FTS region. This relates to the combination of lower matrix strength and higher stress concentration in the FTS regions. The LTS regions act as hard spots, which appear to block the further propagation of the strain bands. These deformation mechanisms shed light on the relevance of the subdivision of the microstructure into FTS and LTS regions during tensile loading and provide a micromechanical justification for considering parameters defined at the level of the FTS and LTS regions in the expressions defining the macroscopic mechanical 
properties of DI. From a more general viewpoint, the successful application of the present methodology to DI indicates that the same methodology could be applied to other material systems to elucidate the effects of similar microstructural heterogeneities.

\section{Acknowledgements}

This work was carried out within the frame of the project "Optimised high performance ductile cast iron using 4D X-ray analysis and microstructural modelling", Danish Research Council for Independent Research, grant no. 10-093966.

\section{References}

[1] N.S. Tiedje, Mater. Sci. Technol. 26 (2010) 505-514.

[2] G. Hütter, L. Zybell, M. Kuna, Eng. Fract. Mech. 144 (2015) 118-141.

[3] D.M. Stefanescu, in: D.M. Stefanescu (Ed.), ASM Handbook, Vol. 1A, Cast Iron Sci. Technol., ASM International, 2017, p. 600.

[4] B. Domeij, J.C. Hernando, A. Diószegi, Metall. Mater. Trans. B Process Metall. Mater. Process. Sci. 49 (2018) 2487-2504.

[5] J.C. Hernando, J. Elfsberg, E. Ghassemali, A.K. Dahle, A. Diószegi, Scr. Mater. 168 (2019) 33-37.

[6] D.O. Fernandino, A.P. Cisilino, S. Toro, P.J. Sanchez, Int. J. Fract. (2017).

[7] D.O. Fernandino, R.E. Boeri, Fatigue Fract. Eng. Mater. Struct. (2019) ffe.13030.

[8] F. lacoviello, V. Di Cocco, C. Bellini, Int. J. Fatigue (2019).

[9] J.H. Liu, X.Y. Hao, G.L. Li, G.S. Liu, Mater. Lett. 56 (2002) 748-755.

[10] Y.B. Zhang, T. Andriollo, S. Fæster, W. Liu, J. Hattel, R.I. Barabash, Acta Mater. 121 (2016) $173-180$.

[11] T. Andriollo, J. Thorborg, J. Hattel, in: Proc. 8th Int. Conf. Comput. Plast. - Fundam. Appl. COMPLAS 2015, 2015.

[12] A. Buljac, C. Jailin, A. Mendoza, J. Neggers, T. Taillandier-Thomas, A. Bouterf, B. Smaniotto, F. Hild, S. Roux, Exp. Mech. 58 (2018) 661-708.

[13] S. Vazehrad, J. Elfsberg, A. Diószegi, Mater. Charact. 104 (2015) 132-138.

[14] F. lacoviello, O. Di Bartolomeo, V. Di Cocco, V. Piacente, Mater. Sci. Eng. A 478 (2008) 181186.

[15] J. Kohout, Mater. Sci. Eng. A 313 (2001) 16-23.

[16] T. Andriollo, Y.B. Zhang, S. Fæster, J. Thorborg, J. Hattel, J. Mech. Phys. Solids 125 (2019) 714735.

[17] Y.B. Zhang, T. Andriollo, S. Fæster, R. Barabash, R. Xu, N. Tiedje, J. Thorborg, J. Hattel, D. Juul Jensen, N. Hansen, Acta Mater. 167 (2019) 221-230. 


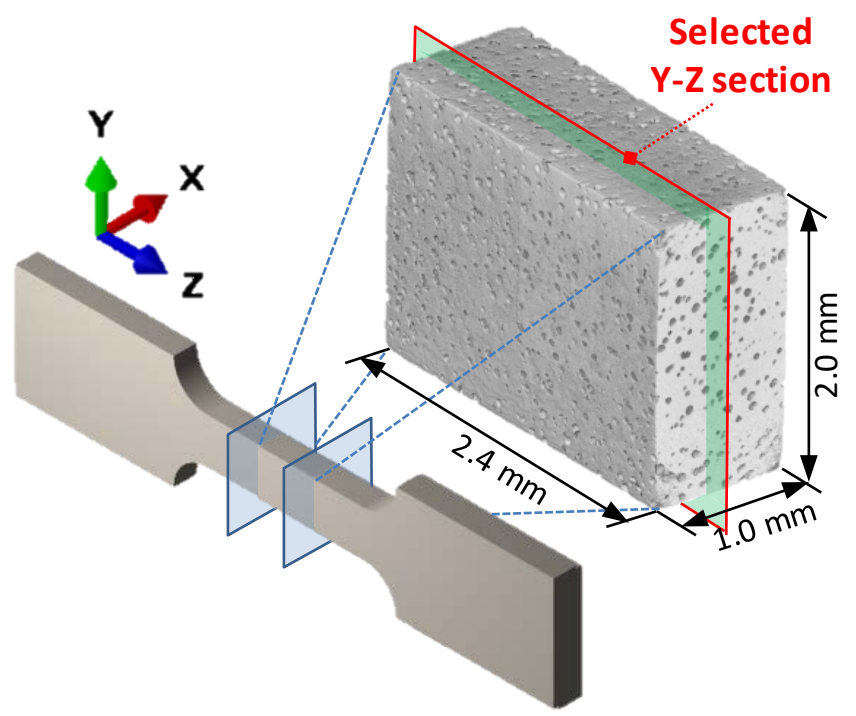

Figure 1: Geometry of the miniaturized tensile specimen with indication of the region imaged with X-ray tomography and the Y-Z section used for color etching.

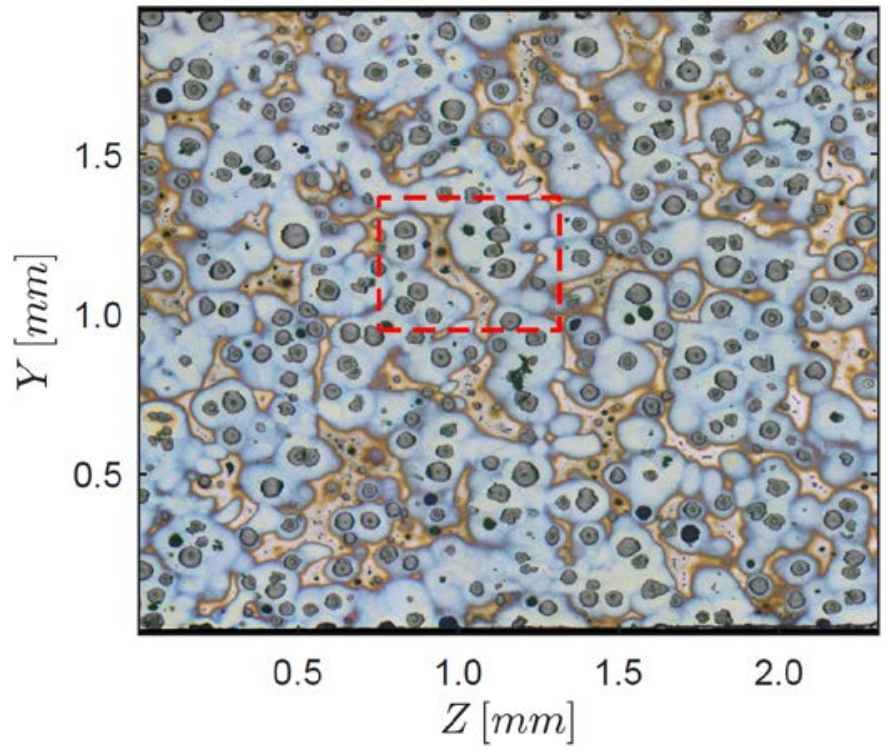

(a)

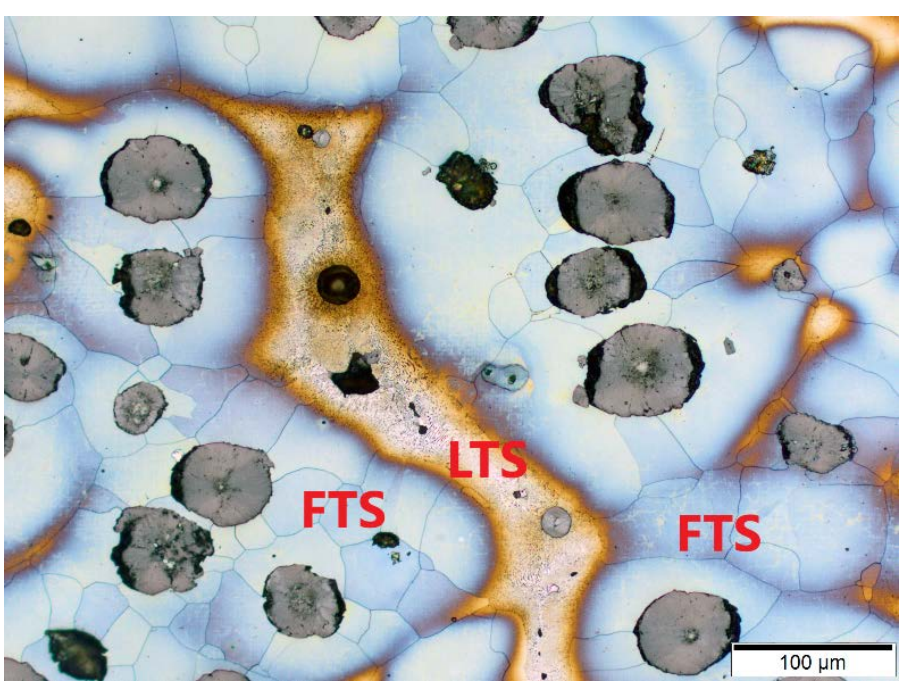

(b)

Figure 2: (a) Optical image of the internal Y-Z section of the specimen - see the schematic in Figure 1 - after color etching. (b) Magnification of the zone inside the red rectangle in (a). 


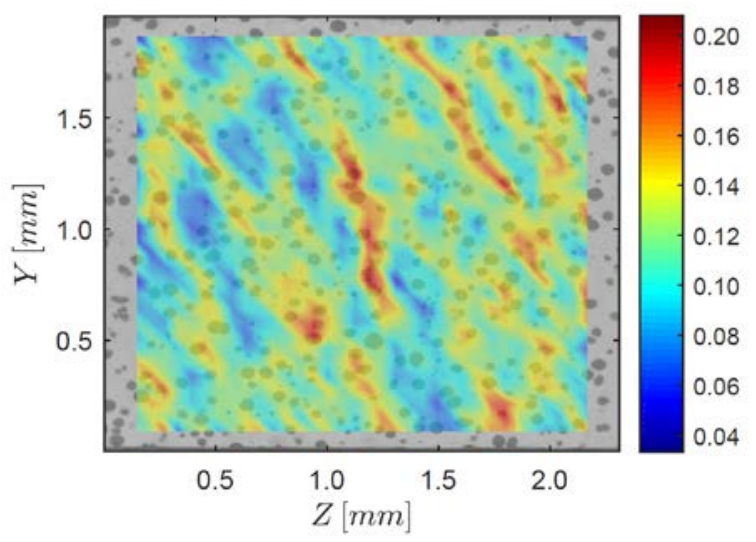

(a)

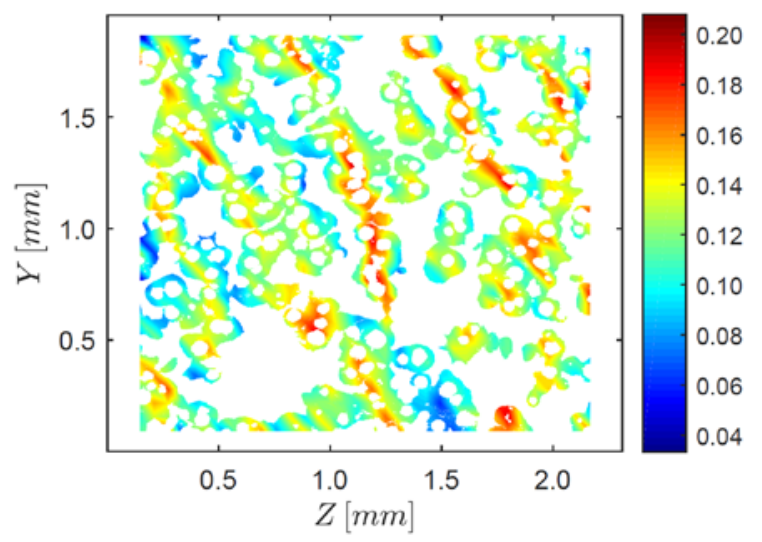

(b)

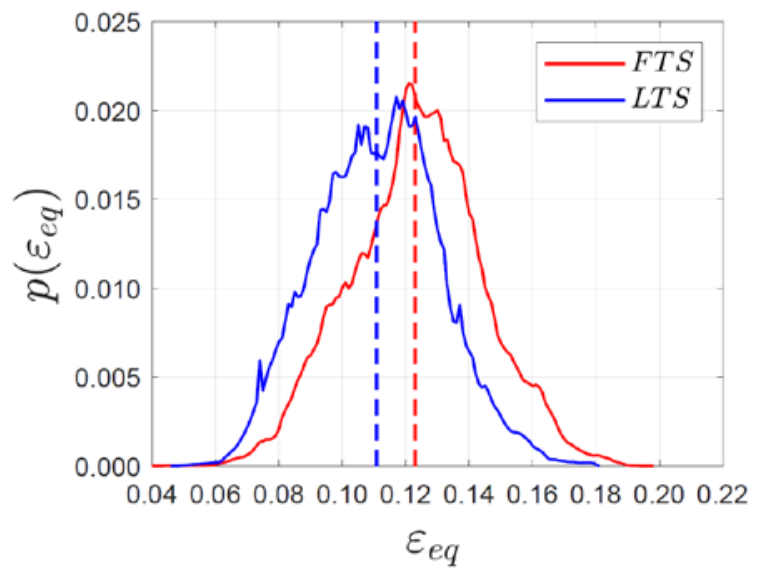

(d)

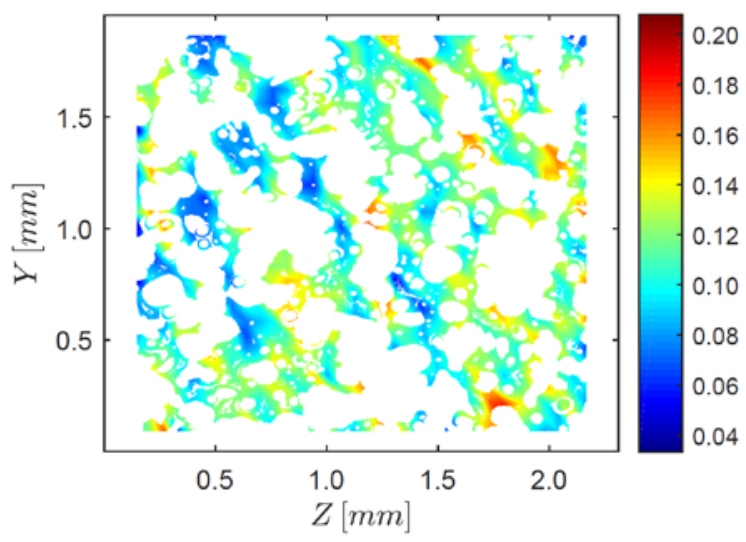

(c)

Figure 3: Equivalent von Mises strain associated with the DVC displacement field. (a) Strain contour over the internal $\mathrm{Y}-\mathrm{Z}$ section of the specimen indicated in Figure 1, superimposed onto the tomography scan. (b) and (c) Same as (a), but showing only the strain values overlapping the part of the matrix belonging to the FTS and LTS regions, respectively. (d) Distributions of the strain values belonging to the contours in (b) and in (c), with the vertical dashed lines indicating the mean values. 


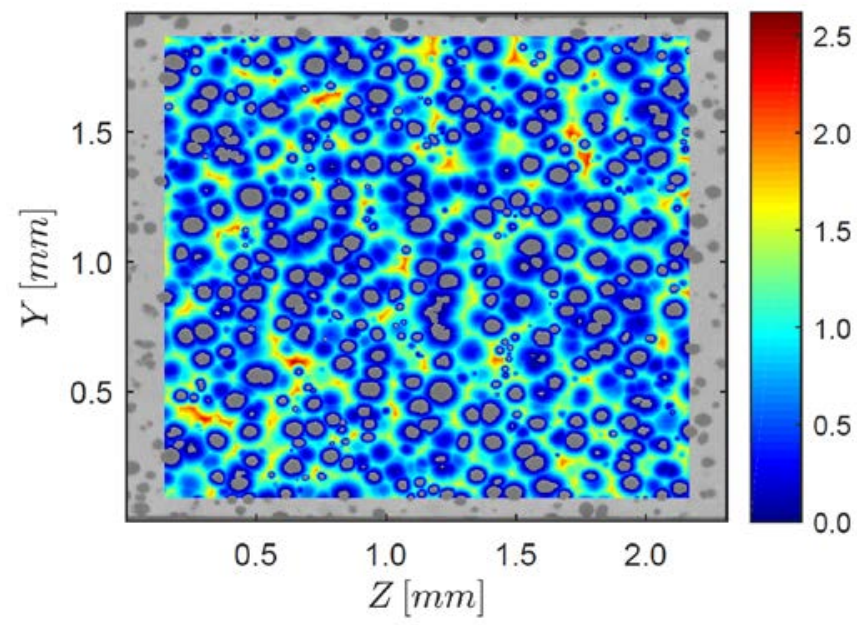

(a)

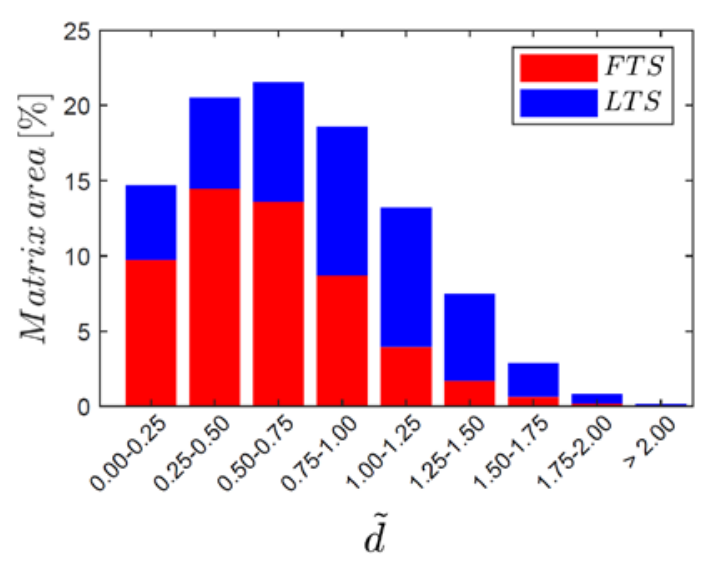

(b)

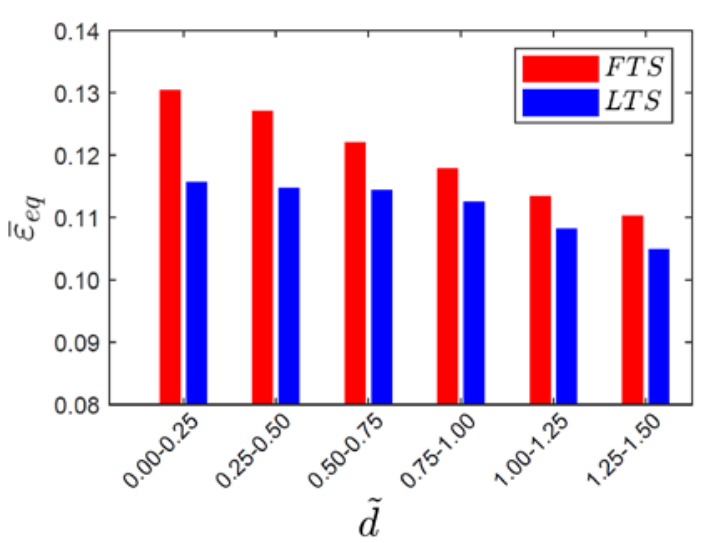

(c)

Figure 4: Normalized 3D distance function $\tilde{d}$ used to estimate the stress concentration in the matrix. (a) Contour of $\tilde{d}$ over the internal Y-Z section of the specimen indicated in Figure 1, superimposed onto the tomography scan. (b) Histogram showing, for each interval of $\tilde{d}$, the area occupied by the corresponding matrix points in the FTS and in the LTS regions. Values are normalized by the total matrix area. (c) Histogram showing, for each interval of $\tilde{d}$, the mean equivalent strain $\bar{\varepsilon}_{e q}$ associated with matrix points in the FTS and LTS regions. 